\title{
Tuberculosis of the distal ulna mimicking malignanacy - a rare case report
}

\author{
Kushwaha $S^{1}$, Kumar $S^{2}$, Deepak $K^{3}$, Singh $S^{4}$, Sharma $V^{5}$ \\ ${ }^{1}$ Dr. Sudhir Shyam Kushwaha, M.S. (Orthopaedics), Senior Resident, ${ }^{2}$ Dr. Kumar Shantanu, M.S.(Orthopaedics), \\ Assistant Professor, ${ }^{3}$ Dr. Deepak Kumar, M.S.(Orthopaedics), Assistant Professor, ${ }^{4}$ Dr. Shailendra Singh, \\ M.S.(Orthopaedics), Assistant Professor, ${ }^{5}$ Prof Vineet Sharma, M.S.(Orthopaedics), FICS, Professor. All are affiliated \\ with King George's Medical University Lucknow, Uttar Pradesh, India
}

Address for Correspondence-Dr.Sudhir Shyam Kushwaha, E-mail-sudhirshyamkushwaha@gmail.com

\begin{abstract}
The tubercular involvement of the long bones of the extremities is very rare so, tuberculosis as a differential diagnosis is usually missed when a patient present with pain and swelling over long bones. The radiology is usually suggestive of the malignancy. We hereby present a case with pain and swelling over the ulna with a suspicion of malignanacy, but biopsy and per-operative findings were suggestive of tuberculosis.
\end{abstract}

Keywords: Tuberculosis, Distal Ulna, long bone.

\section{Introduction}

Tuberculosis still remains a significant problem in the developing countries [1]. Though after the development of the effective antitubercular drugs the prevalence decreased sharply but with the increase in the immunodeficiency states like HIV infection there is resurgence of the cases of tuberculosis [2]. Only a small number of patients with tuberculosis will have osteoarticular involvement [3], half of which will have spinal disease. Tuberculosis of the ulna is extremely rare with very few cases reported till now [4,5]. The authors present a case report of tuberculosis of ulna managed successfully by antitubercular treatment.

\section{Case Report}

A 26 year old female patient presented to our outpatient department with chief complaints of pain and swelling over distal part of the ulna.The patient was having pain with insidious onset since 2 months followed by swelling since one month. The pain was not associated with fever and there were no diurnal variation. The pain was relieved with medication; swelling was about 5X3 $\mathrm{cm}$ in size. The skin overlying swelling was regular and there were no dilated veins. There was no associated

Manuscript received: $08^{\text {th }}$ Jan 2016

Reviewed: $19^{\text {th }}$ Jan 2016

Author Corrected: $29^{\text {th }}$ Jan 2016

Accepted for Publication: $10^{\text {th }}$ Feb 2016 neurovascular deficit initially it was supposed to be a soft tissue tumour and a provisional diagnosis of neoplasm was made.

Anteroposterior and Lateral radiograph of the $(\mathrm{L})$ wrist and forearm shows a radiolucent lytic lesion over the distal part of the ulna with destruction of lateral half of the ulna [1]. Radiologically, in first stance the lesion aroused the suspicion of a malignant tumour destroying the bone with narrow zone of transition then patient was admitted and routine blood investigations were done along with a chest radiograph to see whether there are any signs of lung metastasis and for the purpose of anesthesia fitness too. All blood investigations were within normal limits, except the ESR and CRP was slightly raised.

Based on clinical and radiological examination a provisional diagnosis of tumour was made and the patient was planned for open biopsy of the swelling. On opening the swelling, surprisingly the findings were opposite to what we were expecting.the swelling shows yellow coloured cheesy material which was sent for histopathological examination. The cavity was then curettage, saucerised and thorough lavage was done. Histopathology, confirmed the diagnosis of tubercular osteomyelitis. 
Based on biopsy finding antitubercular treatment was started from next day a below elbow pop slab was applied for three weeks to prevent pathological fracture and after three weeks pop slab was removed and wrist mobilization exercises were promoted. For next one month patient was advised to do works of daily routine only, with the affected limb. Then ATT was continued for total of 18 months.

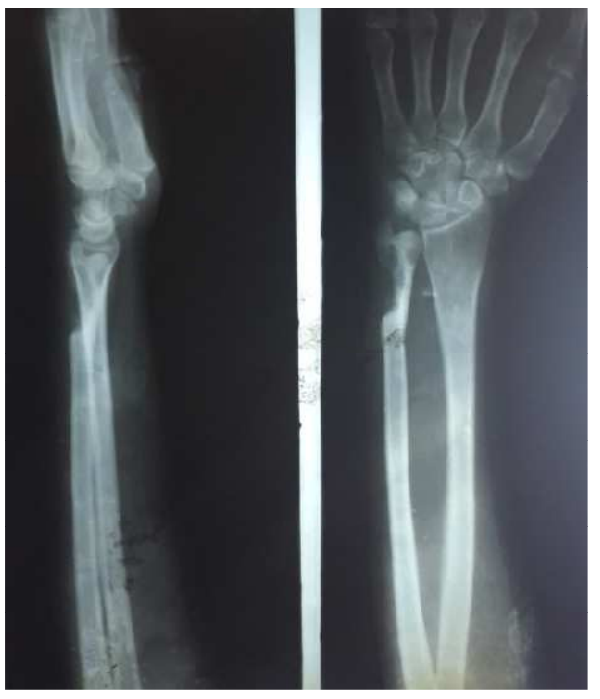

Fig.1: Preoperative x-ray

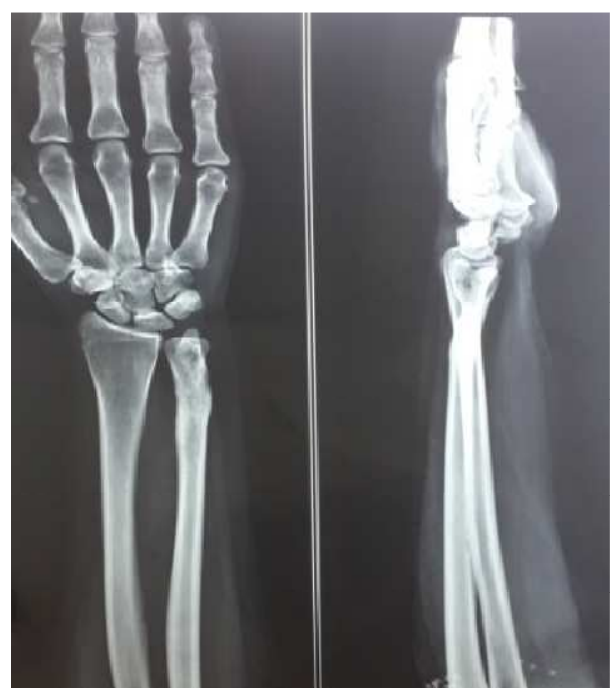

Fig.2: X-ray after 18 months

\section{Outcome and follow up}

After two months of the ATT the patient was having no pain or tenderness and full range of wrist movement. The patient was followed at an average interval of two months and plain radiographs were taken at follow up to see the healing. The patient was followed till the full completion of therapy and patient was doing all activities comfortably.

\section{Discussion}

Tuberculosis has been a major health concern for several thousand years and still millions continue to be affected with this. Crowding, poor sanitation, and malnutrition and poor socioeconomic status are most common association with the disease. Vertebral tuberculosis accounts for 50 percent of the all cases of osteoarticular tuberculosis [1]. Involvement of upper extremity is uncommon and in upper limb most common involvement is of elbow joint [6]. Isolated tuberculosis of the ulna is extremely rare and only few cases have been reported.

Tuberculosis is very notorious in its presentation and may present as a benign lesion to extremely dangerous malignant lesion [7]. Therefore the diagnosis is usually very difficult a combination of suspicion, clinical examination, combined with radiological and biochemical investigation may give a clue to the diagnosis of tuberculosis.

In our case the first provisional diagnosis was of a tumour but the diagnosis came to be of an infective pathology. Therefore, in such radiographic findings the differential diagnosis should include both the tumours and infections [7]. In the literature there are many examples of multifocal tuberculosis of ulna have been reported, however unifocal tuberculosis of ulna is still rare. Sciberras et al have reported a similar case of tubercular osteomyelitis of ulna confined to the styloid [4].

A similar case report of the $\mathrm{TB}$ of ulna mimicking as malignancy was reported by Bidur Gyawali et al, [8] in which conservative ant tubercular treatment results in complete healing of the lesion.

\section{Conclusion}

Tuberculosis can present like neoplastic conditions at unusual site like ulnar diaphysis. So, tuberculosis should always be kept in mind when radiographic investigations are indicative of a neoplastic pathology at these rare sites.

\section{Funding: Nil}

Conflict of interest: None.

Permission of IRB: Yes 


\section{References}

1. Tuli SM. Tuberculosis of the Skeletal System: Bones, Joints, Spine and Bursal Sheaths, 3rd ed. Bangalore: Jaypee Brothers, 2004.

2. David A. Spiegel, M.D., Girish K. Singh, M.D. and Ashok K. Banskota, M.D. Tuberculosis of the Musculoskeletal System. Techniques in Orthopaedics ${ }^{\circledR}$ Lippincott Williams \& Wilkins, Inc., Philadelphia 20(2):167-178 @ 2005.

3. Albalak R, O'Brien RJ, Kammerer JS, O'Brien SM, Marks SM, Castro KG, Moore M. Trends in tuberculosis/human immunodeficiency virus comorbidity, United States, 1993-2004. Arch Intern Med. 2007 Dec 10;167(22):2443-52.

4. Sciberras NC, Lindsay JR. A rare presentation of TB: Osteomyelitis of distal ulna. J Surg Case Rep. 2011 Jan 1; 2011(1):4. doi: 10.1093/jscr/2011.1.4.
5. Shantanu K, Sharma V, Kumar S, Jain S. Unifocal tubercular osteomyelitis of distal ulna: a rare presentation. BMJ Case Rep. 2012 Jan 10; 2012. pii: bcr0820114698. doi: 10.1136/bcr.08.2011.4698.

6.AggarwalA, DhammiIClinical and radiological presen tation of tuberculosis of the elbow. Acta

Orthop Belg. 2006 Jun; 72(3):282-7.

7. Cheung JP, Ho KW, Lam YL, Shek TW. Unusual presentations of osteoarticular tuberculosis in two paediatric patients. BMJ Case Rep. 2012 Oct 19; 2012. pii: bcr2012006714. doi: 10.1136/bcr-2012-006714.

8. Bidur Gyawali, Bishnu Dev Sharma, Nirab Kayastha, Amit Joshi. Tuberculosis Mimicking Bone Tumor. Medical Journal of Shree Birendra Hospital. Jan-June 2012/vol.11/Issue1,49-51.

\section{How to cite this article?}

Kushwaha SS, Kumar S, Deepak K, Singh S Sharma V. Tuberculosis of the distal ulna mimicking malignanacy - a rare case report . Int J Med Res Rev 2016;4(2):264-266. doi: 10.17511/ijmrr.2016.i02.002. 